\title{
Polímeros Usados como Sistemas de Transporte de Princípios Ativos
}

\author{
Patrícia Severino \\ Departamento de Processos Biotecnológicos, Unicamp \\ Faculdade de Ciências da Saúde, UFP \\ Maria Helena A. Santana \\ Departamento de Processos Biotecnológicos, Unicamp \\ Sônia M. Malmonge \\ Centro de Engenharia, Modelagem e Ciências Sociais Aplicadas, UFABC \\ Eliana B. Souto \\ Centro de Genómica e Biotecnologia, UTAD \\ Faculdade de Ciências da Saúde, UFP
}

\begin{abstract}
Resumo: Os diferentes sistemas de transporte têm evidenciado potencial terapêutico para uma grande variedade de princípios ativos, satisfazendo vários requisitos, como a prevenção da sua eliminação rápida do organismo, a redução da sua toxicidade sistêmica, a estabilização e a otimização do seu metabolismo, e o direcionamento específico ao local alvo e os mecanismos de defesa. No entanto, têm sido reconhecidos vários outros desafios associados à liberação específica do princípio ativo ao local alvo, pelo que, para ultrapassar os obstáculos químicos e biológicos, a seleção do polímero utilizado para a preparação do sistema de transporte é de importância crucial. O presente trabalho apresenta um relato sobre os principais polímeros naturais e sintéticos utilizados para a preparação de sistemas de transporte de princípios ativos in vivo.
\end{abstract}

Palavras-chaves: Polímeros sintéticos, polímeros naturais, transporte de princípios ativos.

\section{Polymers for Drug Delivery Systems Formulations}

Abstract: The different carrier systems have shown therapeutic potential for a wide variety of drugs, satisfying multiple requirements, such as prevention of rapid elimination, reducing toxicity, promoting stabilization, optimization of metabolism, drug delivery and defense mechanisms. However, it has been recognized several other challenges associated with the specific release of actives in drug delivery. Therefore, to overcome chemical and biological obstacles, the selection of the polymer used to prepare the transport system is crucial. This paper presents a report on the main natural and synthetic polymers used in the preparation of drug carrier systems in vivo.

Keywords: Synthetic polymers, natural polymers, carrier of drugs.

\section{Introdução}

A investigação científica de novos meios de veiculação de princípios ativos in vivo permitiu o desenvolvimento de vários tipos de sistemas de transporte dos quais se destacam os lipossomas ${ }^{[1]}$, conjugados de polímero e princípios ativos ${ }^{[2]}$, micelas de copolímeros anfipáticos ${ }^{[3]}$, micro e nanopartículas poliméricas ${ }^{[4]} \mathrm{e}$, mais recentemente, as nanopartículas lipídicas sólidas ${ }^{[5]}$.

Os diferentes sistemas de transporte têm evidenciado potencial terapêutico para uma grande variedade de princípios ativos, preenchendo assim vários requisitos, como a prevenção da sua eliminação rápida do organismo ${ }^{[6]}$, a redução da sua toxicidade sistêmica $^{[7]}$, a estabilização e a otimização do seu metabolismo ${ }^{[8]}$, o direcionamento específico ao local alvo ${ }^{[9]}$ e os mecanismos de defesa ${ }^{[10]}$. No entanto, têm sido reconhecidos vários outros desafios associados à liberação específica do princípio ativo ao local alvo, pelo que, para ultrapassar os obstáculos químicos e biológicos, a seleção do polímero utilizado para a preparação do sistema de transporte é de importância crucial.

Para a preparação dos sistemas poliméricos de transporte, pode recorrer-se ao uso de polímeros naturais ${ }^{[11]}$, sintéticos ${ }^{[12]}$ ou semi-sintéticos ${ }^{[13]}$. A seleção do polímero a ser empregado está condicionada, em grande medida pela natureza do princípio ativo que se pretende incorporar no sistema. Assim, quando esta é de natureza hidrofílica ${ }^{[14]}$ recorre-se, em geral, a polímeros de natureza apolar e a preparação do sistema deve proceder em meio não aquoso. Quando se trata de princípios ativos hidrofóbicos ${ }^{[15]}$, deve selecionar um método de preparação em meio aquoso e, para isso, recorre-se, em geral, a polímeros de natureza hidrofílica.

Os sistemas de transporte destinam-se a disponibilizar o princípio ativo ao organismo após a administração. O mecanismo de difusão é responsável pela liberação do princípio ativo seguido da hidrólise do polímero, sendo ideal quando se trata de moléculas relativamente pequenas. Para moléculas de massa molar (MM) elevada, o mecanismo de difusão torna-se muito lento, nessas circunstâncias é requerido um mecanismo de erosão para a liberação das moléculas de princípio ativo ${ }^{[16]}$.

\section{Polímeros Naturais}

Uma grande variedade de polímeros naturais pode ser utilizada para a preparação de sistemas poliméricos de transporte, dos quais de destacam os peptídeos, as proteínas e os polissacarídeos. Os polímeros naturais podem ser utilizados para preparar micropartículas poliméricas, bem como transportadores coloidais,

Autor para correspondência: Eliana B. Souto, Faculdade de Ciências da Saúde, Universidade Fernando Pessoa, Rua Carlos da Maia, 296, CEP: 4200-150, Porto, Portugal, e-mail: eliana@ufp.edu.pt 
isto é, as nanopartículas poliméricas. A maior vantagem da utilização de transportadores coloidais reside na possibilidade de modificarem a distribuição corporal de vários princípios ativos ${ }^{[17,18]}$, bem como no aumento da sua captação celular por parte das células do sistema fagocítico mononuclear, designadamente dos macrófagos ${ }^{[19]}$.

Vantagens desta classe de polímeros incluem a bioadesão a mucosas como ocular, nasal, urinária, gastrointestinal e vaginal, proporcionando biocompatibilidade, biodegradabilidade e, por conseguinte, maior biodisponibilidade dos princípios ativos administrados. A desvantagem é a variação que sofrem em relação aos lotes devido ao processo de obtenção e purificação ${ }^{[20,21]}$.

\section{Peptideos e proteínas}

Dentre os sistemas coloidais, aqueles baseados em peptídeos e proteínas são altamente promissores, uma vez que estas macromoléculas são biodegradáveis e não antigênicas, os sistemas são relativamente fáceis de preparar e a distribuição dos tamanhos de cadeias pode ser facilmente monitorizada ${ }^{[22]}$. Uma vez sendo conhecida a estrutura primária da proteína, os sistemas podem veicular princípios ativos covalentemente ligados à proteína e serem modificadas as suas propriedades de superfície ${ }^{[23]}$.

A albumina é uma proteína de origem animal, obtida a partir do soro humano ou bovino. É solúvel em água e tem um $\mathrm{pK}_{\mathrm{a}}$ de 5,3, que lhe confere um caráter ácido. Esta proteína é um transportador atrativo muito utilizado para preparar microesferas e microcápsulas, devido à sua disponibilidade no estado puro, biodegradabilidade, ausência de toxicidade e de imunogenicidade ${ }^{[24]}$. Um grande número de estudos tem demonstrado que esta proteína se acumula em tumores sólidos ${ }^{[25,26]}$, tornando-se num transportador útil para o direcionamento específico de fármacos antitumorais, como a doxorrubicina $^{[27]}$, curcumina ${ }^{[28]}$, revesratrol ${ }^{[29]}$ entre outros. Deve ressaltar que a albumina é um transportador antialergênico por não ser reconhecida pelo sistema fagocitário ${ }^{[24]}$.

Katti e Krishnamurti ${ }^{[30]}$ prepararam microesferas de albumina por reticulação da proteína com formaldeído na ausência de tensoativo, usando óleo de parafina como meio de dispersão. As microesferas foram caracterizadas por microscopia eletrônica de varredura (MEV), apresentando-se esféricas e com dimensões compreendidas entre 50 e $400 \mathrm{~mm}$. Os estudos de cinética de liberação do princípio ativo (clorotiazida), a partir dos sistemas preparados, demonstraram a ocorrência de um mecanismo de difusão.

Têm sido investigados diferentes polipeptídeos para várias aplicações médicas, como suturas biodegradáveis, substitutos de pele artificiais e sistemas de liberação modificada. A velocidade de biodegradação dos polipeptídeos sintéticos pode ser controlada pela seleção apropriada dos seus aminoácidos ${ }^{[31,32]}$.

\section{Polissacarídeos}

Os polissacarídeos são formados pela condensação de um número elevado de moléculas monossacarídicas (oses), que podem ser do mesmo ou de diferentes tipos. As oses apresentam simultaneamente várias funções alcoólicas e uma função redutora (aldeído ou cetônica). A sua classificação baseia-se, por um lado, no número de átomos de carbono que incluem nas suas moléculas (trioses, tetroses, pentoses, hexoses, heptoses, etc) e, por outro, na natureza da função redutora (aldoses e cetoses). No que diz respeito à preparação dos sistemas poliméricos de transporte de princípios ativos destaca-se a importância da celulose e dos seus derivados, dos alginatos ${ }^{[33]}$, do amido $^{[34]}$, da quitosana ${ }^{[35]}$ e do ácido hialurônico ${ }^{[36]}$.

\section{Celulose e derivados}

A celulose é um polissacarídeo formado por moléculas de glucose, a partir do qual podem ser obtidos diferentes derivados. É usada com frequência como excipiente para a obtenção de formas sólidas de dosagem ${ }^{[37]}$. Como se trata de um polímero insolúvel em água e nos solventes orgânicos, são, em geral, utilizados os seus derivados. Nestes derivados é possível incorporar um grande número de princípios ativos, tanto hidrofílicos, como niacina ${ }^{[38]}$, fenofibrato $^{[39]}$, e hidrofóbicos como o meloxican ${ }^{[40]}$, clozapina $^{[41]}$, repaglidina ${ }^{[42]}$ e permitem ainda estabilizar algumas substâncias fotossensíveis $^{[43]}$.

\section{Alginatos}

Os alginatos fazem parte da família dos polissacarídeos constituídos por resíduos de ácido a-L-glucurónico e ácido b-Dmanúrico, formando homo-polímeros ou co-polímeros. Estes polímeros são hemocompatíveis e não sofrem acumulação em qualquer órgão após a administração ${ }^{[44]}$. Na literatura são encontradas várias utilizações de alginato de cálcio em sistemas de liberação modificada ${ }^{[45,46]}$. A velocidade de liberação do princípio ativo incorporado em micropartículas de alginato de sódio parece ser afetada pelo tipo de agente de reticulação utilizado no método de preparação ${ }^{[47]}$. Encontram-se disponíveis na literatura vários métodos de preparação de microesferas de alginato de sódio, preferencialmente utilizados para incorporar princípios ativos hidrofílicos ${ }^{[48,49]}$.

\section{Amido}

O amido é um polissacarídeo formado, na maior parte dos casos, por dois constituintes, a amilose e a amilopectina. O primeiro é um polissacarídeo de cadeia linear, formada por unidades de D-glucose ligadas entre si por ligações a-1,4 glucosídicas, com valores de MM que varia entre 150000 a $600000 \mathrm{Da}$. Estas cadeias apresentam um comprimento variável e podem associar-se por intermédio de ligações de hidrogênio que se estabelecem entre as hidroxilas, formando assim estruturas bastante compactas ${ }^{[50]}$. O segundo é formado por cadeias principais idênticas às da amilose, mas às quais se ligam mediante ligações a-1,6 glucosídicas as cadeias laterais, cujo comprimento varia entre 20 a 25 unidades de D-glucose. A MM da amilopectina pode atingir milhões de Dalton. O uso de microesferas baseadas em amido foi sugerido para embolização ${ }^{[51]}$, administração parenteral e administração nasal ${ }^{[52]}$ de diferentes princípios ativos.

\section{Quitosana}

A quitosana é um polímero hidrofílico, obtido pela hidrólise alcalina dos grupos $N$-acetilglucosamina da quitina, a qual é abundante nos exoesqueletos de insetos e de crustáceos. É um polímero semelhante à celulose, apresentando grupos amina na posição $C_{2}$ em vez dos grupos hidroxilas. Os grupos aminas conferem ao polímero uma densidade de carga eletrostática elevada, tornando-o disponível para reações químicas e formação de sais ${ }^{[53]}$.

Calvo et al. ${ }^{[54]}$ prepararam nanopartículas de quitosana, o qual é adequado para incorporar proteínas. A reação de preparação de nanopartículas de quitosana (catiônica) e de tripolifosfato (aniônico) revestidas com cadeias hidrofílicas de poli(óxido de etileno) (PEO).

Para aumentar a estabilidade termodinâmica das microesferas de quitosana, estas podem ser revestidas igualmente com polissacarídeos aniônicos, como a carboximetil lecitina ou com multicamadas lipídicas (dipalmitoilfosfatidilcolina). Têm sido incorporadas em partículas de quitosana sensíveis ao $\mathrm{pH}$, diferentes tipos de princípios ativos, como por exemplo, diclofenaco de sódio $^{[55]}$ e isoniazida ${ }^{[56]}$. 


\section{Polímeros Sintéticos}

Têm sido utilizados diferentes tipos de polímeros sintéticos para a preparação de sistemas de transporte de princípios ativos. Dependendo do tipo de aplicação terapêutica requerido podem ser utilizados polímeros biodegradáveis, isto é, capazes de sofrerem degradação em meio fisiológico e não biodegradáveis. Os polímeros biodegradáveis apresentam numerosas vantagens sobre os não biodegradáveis, uma vez que não necessitam de remoção cirúrgica após o esgotamento do princípio ativo, podem fornecer um meio de liberação direta da substância à circulação sistêmica e o polímero e o princípio ativo podem ser combinados em várias formas ${ }^{[57]}$. Os polímeros sintéticos mais utilizados para a preparação de sistemas de transporte de princípios ativos são os polianídridos alifáticos, os poliorganofosfazenos, o poliestireno, os poliacrilatos e seus derivados e ainda os poliésteres alifáticos ${ }^{[58]}$.

Os polímeros sintéticos apresentam um custo mais elevado e potencial antigênico, podendo manifestar toxicidade quando degradados ou hidrolisados, mas mantém-se a reprodutibilidade em cada lote sendo, por isso, mais seguro para veiculação de princípios $\operatorname{ativos}^{[59,60]}$

\section{Polianidridos alifáticos}

Os polianidridos alifáticos são polímeros biodegradáveis, derivados de ácidos graxos, que têm sido utilizados para liberação modificada de vários princípios ativos ${ }^{[61]}$. $\mathrm{O}$ seu interesse tem aumentado nos últimos anos, uma vez que são não mutagênicos, não citotóxicos e não teratogênicos ${ }^{[62,63]}$. Foi ainda demonstrada a sua biocompatibilidade e biodegradabilidade no cérebro ${ }^{[64,65]}$.

Sistemas de polianídridos alifáticos têm sido desenvolvidos para a liberação modificada de princípios ativos a nível parenteral ${ }^{[66]}$. A degradação destes sistemas depende de sua MM e ocorre praticamente por erosão, obedecendo a cinética de ordem zero para os princípios ativos incorporados ${ }^{[67,68]}$. A sua eliminação do organismo requer a degradação do polímero em moléculas solúveis em água, que são posteriormente excretadas ${ }^{[69]}$.

Os polianidridos são compostos, em geral, por monômeros de um diácido hidrossolúvel, cuja eliminação por dissolução é lenta ${ }^{[70]}$. Para ultrapassar esta limitação têm sido estudados sistemas preparados com polianidridos do ácido sebácico com 1,3-bis(pcarboxifenoxi) propano) (P(CPP-SA)) ou com um dímero de ácido erúcico (P(FAD-SA)).

Apesar dos numerosos estudos, a composição destes polímeros não fornece uma elevada capacidade de liberação de princípios ativos a células ou órgãos específicos. Para atingir esta finalidade, é necessário o acoplamento com ligantes capazes de reconhecimento celular, como, por exemplo, os anticorpos monoclonais. O reconhecimento dos ligantes específicos, que se encontram à superfície dos sistemas de transporte pelo órgão específico ou pelos receptores celulares, pode resultar no aumento do direcionamento do princípio ativo e na captação por endocitose do complexo ligante-receptor ${ }^{[66,71]}$.

Gao et al. ${ }^{[72]}$ descreveram um mecanismo de modificação covalente da superfície de microesferas de poli(ácido sebácico) com ligantes contendo grupos amina. Estes últimos reagem com grupos anidrido da superfície, formando-se uma ligação covalente através de uma ligação amida. Esta modificação de superfície constitui um procedimento de uma única etapa que requer uma pequena quantidade de ligante, que pode, por sua vez ser controlada pela sua concentração na solução. Os ligantes livres na superfície podem interagir com os seus receptores em solução, conseguindo-se ainda uma variedade de ligantes contendo grupos amina.

\section{Poliorganofosfazenos}

Os poliorganofosfazenos são uma classe de polímeros com aplicação médica e farmacêutica ${ }^{[73,74]}$. Estes polímeros possuem a cadeia principal inorgânica, formada por átomos de fósforo e de nitrogênio dispostos alternadamente. $\mathrm{O}$ interesse por este reside no fato das suas propriedades fisico-químicas dependerem principalmente da natureza dos substituintes do átomo de fósforo ${ }^{[75]}$.

Com o objetivo de aplicação como biomateriais, foram sugeridos como grupos substituintes, diferentes aminoácidos, uma vez que estes últimos conferem biocompatibilidade e biodegradabilidade ao polímero. Além disso, a presença do grupo imidazol parece aumentar a degradação hidrolítica originando intermediários relativamente estáveis e, finalmente, moléculas fisiológicas de baixo valor de $\mathrm{MM}^{[76]}$

Allcock et al. ${ }^{[77,78]}$ prepararam derivados de poliorganofosfazenos para várias aplicações biomédicas. Foram preparadas nanopartículas de poliorganofosfazenos revestidas com PEO, de diâmetro compreendido entre 100 e $120 \mathrm{~nm}$, para prolongar o tempo de circulação sanguínea.

Caliceti et al. ${ }^{[79]}$ sintetizaram um poliorganofosfazeno composto por fenilalanina etil éster/imidazol/cloro na proporção 75/7/18 para a preparação de filmes de liberação modificada de naproxeno. $\mathrm{O}$ sistema liberou o princípio ativo por um longo período de tempo, em concentrações adequadas para o tratamento de inflamações tanto agudas como crônicas. No entanto, este polímero parece ser inadequado para a preparação de microesferas, e portanto, os autores utilizaram fenilalanina etil éster/imidazol nas proporções de 71/29 e 80/20, como substituintes do fósforo na cadeia principal do polifosfazeno.

Os poliorganofosfazenos têm sido investigados para veicular princípios ativos de baixo valor de MM. Recentemente, Caliceti et al. ${ }^{[80]}$ demonstraram que estes polímeros são igualmente adequados para veicular proteínas. Os autores incorporaram insulina num derivado organofosfazeno de fenilalanina etil éster/ imidazol na proporção de 80/20. A liberação da proteína ocorreu de forma rápida nas duas primeiras horas, tornando-se mais lenta nas seguintes 2-70 horas. Não foi observado o esgotamento completo da matriz em hormônio. Esta encontra-se fisicamente ligada à rede polimérica, pelo que, é provavelmente liberada por um mecanismo de erosão que ocorre muito lentamente.

\section{Poliestireno}

O poliestireno é um polímero não biodegradável, que origina micropartículas de superfície hidrofóbica, pela polimerização do estireno a temperaturas elevadas $\left(80^{\circ} \mathrm{C}\right)^{[81]}$. Foram desenvolvidas igualmente nanopartículas de poliestireno apresentando superfície hidrofílica, por polimerização através de radicais livres entre monômeros hidrofílicos e monômeros hidrofóbicos de estireno ${ }^{[82]}$.

$\mathrm{O}$ interesse do poliestireno resume-se à sua aplicabilidade em estudos in vitro e in vivo que se ocupam da caracterização físico-química dos sistemas poliméricos de transporte. São usadas micro e nanopartículas de poliestireno para explorar o sistema reticuloendotelial (RES) e ainda para avaliar a estabilidade dos sistemas na corrente sanguínea, a captura hepática e esplênica, biodistribuição sistêmica e a captação pelas placas de Payer após administração oral ${ }^{[83]}$.

As nanopartículas de poliestireno podem ser protegidas da captura pelo fígado e baço, através da adsorção de copolímeros diblocos anfipáticos, prolongando desta forma o tempo de residência na corrente sanguínea ${ }^{[84,85]}$. O aumento da hidrofilicidade da superfície do sistema resulta numa redução da fagocitose por parte dos macrófagos circulantes. Quanto à carga elétrica, a carga 
positiva parece aumentar a captação e a internalização celular, enquanto que a carga negativa reduz a captação. Foi demonstrado que as microesferas de poliestireno com albumina de soro bovino adsorvida à superfície apresentam maior tempo de residência na corrente sanguínea, do que as que contêm fibronectina à superfície ${ }^{[86]}$.

\section{Poliacrilatos e derivados}

Os poliacrilatos são formados a partir da polimerização do ácido acrílico, sendo que os mais utilizados na tecnologia farmacêutica são os carbômeros ou Carbopol ${ }^{\circledR}$ e os polimetacrilatos ou Eudragit ${ }^{\circledR}$.

Os carbômeros ou Carbopol ${ }^{\circledR}$ são polímeros sintéticos do ácido acrílico, de elevado valor de MM, reticulados com alilsacarose ou alilpentaeritrol. São extensamente utilizados em produtos destinados à aplicação não parenteral. Estes polímeros apresentam propriedades mucoadesivas $^{[87]} \mathrm{e}$, por esta razão, são utilizados para prolongar o tempo de residência no trato gastrointestinal de numerosos princípios ativos. Um importante fator para a bioadesão é o tamanho das partículas do sistema de transporte. As propriedades bioadesivas são otimizadas pela redução das dimensões das micropartículas, o que promove o aumento da força de adesão e/ou ao prolongamento do tempo de trânsito gastrointestinal, resultando num aumento da biodisponibilidade do princípio ativo ${ }^{[48]}$.

Kriwet et al. ${ }^{[88]}$ prepararam micro e nanopartículas poliacrílicas com propriedades bioadesivas, usando o método de polimerização invertida para incorporar princípios ativos hidrofílicos, na presença de dimetacrilato de etilenoglicol como agente de reticulação. Os resultados demonstraram que as partículas polimerizadas apresentavam as mesmas propriedades mucoadesivas do que as de policarbofilo, usadas como referência. A adição de princípio ativo ou do agente de reticulação não afetou as propriedades adesivas dos sistemas obtidos.

Um tipo especial de poliacrilatos diz respeito aos polimetacrilatos ou Eudragit ${ }^{\circledR[89]}$. São polímeros catiônicos e aniônicos sintéticos, de dimetilaminoetilmetacrilatos, ácido metacrílico e ésteres do ácido metacrílico, em várias proporções. A Farmacopéia Americana (USP) descreve três tipos de copolímeros do ácido metacrílico (Tipo A, Tipo B e Tipo C), que variam no conteúdo em ácido metacrílico e na viscosidade em solução. O Eudragit ${ }^{\circledR}$ RL (Tipo A) ${ }^{[90]}$ e o Eudragit ${ }^{\circledR} R S$ (Tipo B $)^{[91]}$ são referidos como copolímeros de metacrilato de amônio. Estes polímeros são utilizados para prolongar o tempo de residência das substâncias ativas no trato gastrointestinal. Os sistemas poliméricos de transporte podem ser preparados a partir dos polímeros já formados ${ }^{[92]}$ ou a partir de reações de polimerização dos seus monômeros ${ }^{[93]}$.

Fundueanu et al. ${ }^{[94,95]}$ prepararam microesferas de polímeros acrílicos para a liberação controlada de antidiabéticos orais, por polimerização em suspensão do ácido metacrílico e do metilmetacrilato, na presença de dimetacrilato de etilenoglicol como agente de reticulação. O primeiro monômero apresenta um caráter aniônico, permitindo a formação de complexos iônicos com princípios ativos mais alcalinos, e o segundo fornece à matriz polimérica um caráter hidrofóbico, permitindo ao princípio ativo uma cinética de liberação modificada.

\section{Poliésteres alifáticos}

A classe de polímeros mais extensamente estudada para a preparação de sistemas poliméricos de transporte de princípios ativos diz respeito aos poliésteres alifáticos. São representados pelos poli(ácido láctico) (PLA), poli(ácido glicólico) (PGA) e seus copolímeros (PLGA), além de diferentes poliésteres alifáticos, como os poli( $\alpha$-hidroxiácidos), os poli( $\beta$-hidroxiácidos) e a $\operatorname{poli}(\alpha \text {-caprolactona })^{[96]}$.
Os poliésteres alifáticos são um grupo de polímeros sintéticos, não tóxicos e biodegradáveis que, em ambiente aquoso sofrem degradação hidrolítica mediante clivagem de ligações éster originando ácidos hidroxicarboxílicos atóxicos. Estes últimos são metabolizados em dióxido de carbono e água, via ciclo do ácido cítrico. Em geral, os valores de MM média destes variam desde 2000 a valores superiores a 100.000 Da. Variando as condições de preparação e a proporção dos diferentes monômeros, o polímero resultante pode exibir diferentes cinéticas de liberação, desde vários meses a anos ${ }^{[97,98]}$.

A biodegradação dos poliésteres alifáticos parece ocorrer em quatro etapas consecutivas: hidratação, degradação inicial, degradação posterior e solubilização. Na etapa de hidratação, o meio aquoso em que o polímero se encontra penetra na matriz polimérica, resultando no relaxamento das cadeiras do polímero que é acompanhado da diminuição da temperatura de transição vítrea $\left(T_{\mathrm{g}}\right)$. A degradação inicial começa na região hidratada do polímero através da hidrólise da ligação éster, resultando na clivagem da cadeia principal do polímero e na redução da MM do mesmo. A hidrólise continua no interior da matriz hidratada de tal forma que a MM do polímero diminui continuamente, embora mantenha a sua integridade. Na etapa de degradação posterior, a cadeia polimérica continua a ser hidrolisada e a sua MM diminui até um ponto em que não consegue manter a sua integridade. Em consequência, inicia-se a perda da massa do polímero. Na etapa final, os fragmentos de polímero originam moléculas hidrofílicas que são solúveis no meio aquoso ${ }^{[99]}$.

Os fatores que influenciam a biodegradação dos poliésteres alifáticos dizem respeito à composição polimérica (proporção de ácidos láctico e glicólico), $\mathrm{MM}, \mathrm{pH}$ e força iônica do meio ${ }^{[74]}$. $\mathrm{O}$ grau de cristalinidade do polímero tem um efeito significativo na velocidade de biodegradação. A velocidade de biodegradação é maior para os poliésteres alifáticos com maior proporção em ácido glicólico, isto é, de menor cristalinidade, bem como para o polímero de menor MM. Um meio básico parece reduzir a velocidade de biodegradação dos poliésteres alifáticos em comparação com um meio ácido, devido ao facto de serem originados íons $\mathrm{H}^{+}$que reduzem o $\mathrm{pH}$ do meio $^{[100]}$.

O poliéster alifático mais importante nos dias de hoje é o PLA que, por degradação origina ácido láctico, um metabolito natural do corpo humano. A formação de metabolitos naturais é vantajoso uma vez que o organismo apresenta vias naturais para a sua eliminação $0^{[101]}$.

Albertsson et al. ${ }^{[102]}$ desenvolveram poliésteres alifáticos para várias aplicações. Estes investigadores utilizaram monômeros cíclicos de lactonas, carbonatos anídridos, éter-lactonas e especificamente oxepam-2,7-diona (AA), $\beta$-propiolactona, poli- $\varepsilon$ caprolactona (PCL), 1,5-dioxepano-2-ona [poli(DXO)], poli(DLláctico) (DL-PLA), e 1,3-dioxano-2-ona (TMC). O trabalho envolveu a síntese de monômeros não disponíveis comercialmente, estudos de polimerização para formar homo-polímeros, copolímeros anfipáticos, polímeros reticulados, modificações das propriedades de superfície dos sistemas e sua caracterização. Os copolímeros de poli(DXO) e DL-PLA foram sintetizados em diferentes proporções molares. A técnica de ressonância magnética nuclear (H-NMR) foi utilizada para determinar a composição molar dos copolímeros e a calorimetria diferencial exploratória (DSC) foi utilizada para determinar a $T_{\mathrm{g}}$ e o ponto de fusão. Todos os polímeros apresentaram-se amorfos com uma $T_{\mathrm{g}}$ compreendida entre $-36{ }^{\circ} \mathrm{C}$ [poli(DXO)] e $+55^{\circ} \mathrm{C}$ [poli(DL-PLA $\left.)\right]$. Nos estudos de hidrólise in vitro, os co-polímeros evidenciaram tempos de degradação superiores a 250 dias. 
Têm sido estudados poliésteres alifáticos formados com diferentes proporções de monômeros DL-ácido láctico e glicólico. Diaz et al. ${ }^{[103]}$ incorporaram calcitonina bovina marcada com ${ }^{125} \mathrm{I}$, em três copolímeros de PLGA. O copolímero de menor MM (proporção 45/55) resultou em partículas de menores dimensões, de menor distribuição de tamanhos, e com uma liberação do princípio ativo mais lenta do que o copolímero de maior MM (proporção 60/40), apresentando características de liberação sustentada para terapia a longo prazo.

A superfície dos sistemas poliméricos de transporte pode ser modificada através da adsorção de cadeias poliméricas hidrofílicas, como o poli(etileno glicol) (PEG) ${ }^{[104]}$, os copolímeros poli(óxido de propileno)-poli(óxido de etileno) (PPO-PEO) ou os copolímeros anfipáticos ${ }^{[105]}$. O PEG e o PEO são polímeros idênticos, diferindo apenas no fato de que os grupos metoxi no PEO substituem os grupos hidroxilo terminais no PEG. O PEG apresenta numerosas vantagens tais como a elevada solubilidade em água e em solventes orgânicos, biocompatibilidade, ausência de toxicidade e não é imunogênico. A conjugação de PEG com proteínas demonstrou aumentar o tempo de residência sanguínea e diminuir a sua imunogenicidade e antigenicidade.

O revestimento de nanoesferas com PEG protege as mesmas da interacção com componentes do sangue, prolongando dessa forma o tempo de circulação sanguínea, pelo que poderão funcionar como "depósitos" sanguíneos de princípios ativos ${ }^{[106]}$.

Os copolímeros sintéticos têm sido utilizados para formar conjugados de polímero e princípio ativo, micelas de copolímeros, micro $^{[86]}$ e nanopartículas ${ }^{[3]}$. São formados por duas ou mais unidades monoméricas, seguidas da polimerização e rearranjadas de uma maneira específica dependendo do tipo de copolímero desejado.

Os copolímeros empregados são, em geral, copolímeros em bloco, que consistem num bloco ou sequência de uma unidade repetida acoplada a um bloco de outra unidade repetida. A vantagem da utilização de copolímeros em bloco sobre os copolímeros aleatórios reside no fato do valor da MM dos primeiros ser melhor controlado através das técnicas de polimerização iônica usadas para a síntese do copolímero. Para o segundo tipo, são empregados com frequência, as técnicas de condensação ou polimerização por radicais livres, originando polímeros com distribuição de valores de MM mais larga. A presença de um segundo ou terceiro bloco, especialmente se um deles é hidrofílico enquanto que o outro é hidrofóbico, permite manipular as propriedades do polímero, nomeadamente a composição, a distribuição de $\mathrm{MM} \mathrm{e}$ ainda a proporção de comonomeros conseguindo-se uma grande versatilidade de copolímeros.

Os copolímeros anfipáticos do tipo dibloco ou tribloco, quando em meio aquoso, podem reorganizar-se em micelas e em nanopartículas. Estas nanopartículas apresentam uma forma esférica, com diâmetro médio compreendido entre 20 e $200 \mathrm{~nm}$, podendo ser utilizadas para prolongar o tempo de residência na circulação sanguínea e para liberação sustentada de vários princípios ativos ${ }^{[107]}$.

As contrário dos tensoativos que formam micelas em meio aquoso, os copolímeros diblocos que formam nanopartículas podem não ser solubilizados quando colocados diretamente em contato com o meio aquoso. Por esta razão, os copolímeros dibloco são dissolvidos num solvente orgânico miscível na água, tal como a $N, N$ '-dimetilacetamida e, quando dialisados contra a água, formam as nanopartículas. Em alternativa, os copolímeros diblocos podem ser dissolvidos num solvente orgânico imiscível na água, como o clorofórmio e, em seguida, emulsificados com uma fase aquosa. Por evaporação do solvente volátil são formadas as nanopartículas ${ }^{[108]}$.

O bloco hidrofílico normalmente utilizado é PEO, enquanto que os blocos hidrofóbicos incluem os poli(L-aminoácidos), o poli(L- ácido láctico) e os polialquilcianoacrilatos. Os valores de MM dos diblocos ou triblocos varia entre 2.000 a 20.000 Da.

Em solução aquosa, os agregados micelares consistem num núcleo hidrofóbico envolvido por uma parede polimérica hidrofílica. $\mathrm{O}$ núcleo da micela atua como um microreservatório para a incorporação de princípios ativos hidrofóbicos, enquanto que a parede polimérica externa serve como uma interface entre o núcleo hidrofóbico da micela e o ambiente exterior. As micelas de diblocos podem ser igualmente formadas a partir de diblocos que incluem sequências hidrofóbicas e sequências carregadas ou hidrofílicas. Neste caso, o bloco carregado interage com a porção de fármaco carregada formando um núcleo neutro no interior da micela. O comprimento da cadeia do bloco hidrofóbico é, em geral, menor ou igual ao comprimento da cadeia do bloco hidrofílico.

Devido à biocompatibilidade dos copolímeros de PEO com poli(L-ácido láctico) (PLA) ou com poli( $(\alpha$-benzil-Laspartato) (PBLA), têm sido descritas na literatura várias aplicações. Os grupos aldeído na superfície das micelas de PEO-PLA podem reagir com os resíduos de lisina das proteínas das células. Poderão portanto, ser utilizados para estabelecer a ligação com aminoácidos. Os grupos hidroxilo na superfície das micelas de PEO-PBLA podem ser posteriormente derivados e conjugados com moléculas capazes de guiar as micelas modificadas a locais específicos no organismo vivo. Tais nanoesferas têm sido testadas como veículo para princípios ativos anti-inflamatórios e anti-tumorais.

Devido à separação microfásica e ao rápido intumescimento após exposição à água, este tipo de polímeros possui propriedades interessantes para a encapsulação de macromoléculas hidrofílicas. Uma vez que o $\mathrm{pH}$ no interior das estruturas formadas mantemse relativamente estável durante a incubação, é pouco provável a ocorrência de fenômenos autocatalíticos.

Em geral, um processo de erosão envolve a penetração de água, a hidrólise das ligações éster com formação de moléculas hidrossolúveis, e a perda de massa do polímero. No sentido de comparar as propriedades de erosão dos copolímeros triblocos e o PLGA, Witt e Kissel ${ }^{[109]}$ prepararam microesferas de L-PLGA-PEOL-PLGA em diferentes proporções do bloco hidrofílico (PEO). Para a primeira etapa do processo de erosão, tensão superficial é um fator importante, uma vez que descreve a molhabilidade do sistema e pode ser determinada através de medidas de ângulo de contato. $\mathrm{O}$ efeito do conteúdo de PEO torna-se evidente nos perfís de flutuação a partir de $20 \%$ de PEO. O ângulo de contato diminui à medida que aumenta o conteúdo molar de PEO no copolímero tribloco; e para o mesmo conteúdo molar, o aumento do comprimento das cadeias de PEO faz diminuir igualmente o ângulo de contato. $\mathrm{O}$ valor de MM diminui proporcionalmente à erosão, e o pH no interior da matriz mantém-se estável, sem ocorrer acumulação de produtos de degradação acídicos no interior do sistema. O processo de difusão é também influenciado pela geometria, no entanto neste sistema, o primeiro é desprezível comparativamente à erosão. Note-se que o PLGA é mais hidrofóbico do que o copolímero tribloco. Os autores verificaram que a superfície dos implantes de PLGA se mantinha lisa ao fim de 20 dias de incubação, enquanto que a degradação começava imediatamente após a incubação formando-se produtos ácidos que eram liberados para o meio, resultando na diminuição do pH e aceleração da degradação autocatalítica. Os PLGA degradamse mais rapidamente do que os copolímeros tribloco, embora nos primeiros, a geometria do sistema apresente uma forte influência na velocidade de erosão.

\section{Conclusão}

Inovações em métodos de síntese, modificação e caracterização de polímeros permitem viabilizar e ampliar o uso destes materiais 
em sistemas de transporte de princípios ativos. Baseado em conhecimentos multidisciplinares, o sucesso no desenvolvimento de tais sistemas depende da combinação de técnicas da ciência e engenharia dos materiais, medicina, biologia celular e molecular, bem como nanotecnologia. Particularmente os polímeros bioreabsorvíveis de origem natural ou sintética vêm sendo amplamente estudados para emprego nesta área. A melhor compreensão dos fatores que influenciam sua biodegradação, bioreabsorção e a forma com que interagem com os elementos biológicos permite promover as modificações necessárias para que os dispositivos atendam aos requisitos de cada aplicação e princípio ativo específicos, bem como viabilidade técnica e econômica para fabricação e uso em larga escala.

\section{Agradecimentos}

Os autores agradecem a Fundação de Amparo a Pesquisa do Estado de São Paulo (FAPESP/Brasil) e a Coordenação de Aperfeiçoamento de Pessoal de Nível Superior (Capes, Brasil). No âmbito deste projeto, os autores também agradecem a Fundação para a Ciência e a Tecnologia (FCT) ao abrigo da referência PTDC/ SAU-FAR/113100/2009.

\section{Referências bibliográficas}

1. Parmar, J.J.; Singh, D.J.; Hegde, D.D.; Lohade, A.A.; Soni, P.S.; Samad, A. \& Menon, M.D. -Indian J. Pharm. Sci.,72, p.442 (2010).

2. Valero, M.; Perez-Revuelta, B.I. \& Rodriguez, L.J. - Int. J. Pharm.,6, p.97 (2003). http://dx.doi.org/10.1016/S0378-5173(02)00664-6

3.Karavelidis, V.; Giliopoulos, D.; Karavas, E. \&Bikiaris, D. - Eur. J. Pharm. Sci.,23, p.636 (2010).PMid:20863892. http://dx.doi.org/10.1016/j. ejps.2010.09.004

4. Men, K.;Zeng, S.; Gou, M.; Guo, G.; Gu, Y.C.; Luo, F.; Zhao, X.;Wei, Y. \&Qian, Y. - J. Biomed. Nanotechnol.,6, p.292 (2010).

5. Aji Alex, M.R.; Chacko, A.J.; Jose, S. \&Souto, E.B. - J. Pharm. Sci., 18, p.11 (2010).

6. Midhun, B.T.; Shalumon, K.T.; Manzoor, K.; Jayakumar, R.; Nair, S.V. \&Deepthy, M. J. - Biomater. Sci. Polym. (2010) In press.

7. Kang, J.W.; Davaa, E.; Kim, Y.T. \& Park, J.S. - J. Drug $\begin{array}{llll}\text { Target., } & 18, & \text { p.637 (2010).PMid:20192816. http://dx.doi. }\end{array}$ org/10.3109/10611861003649712

8. Zhang, P.; Chen, L.; Zhang, Z.; Lin, L. \& Li, Y. - J. Nanosci. Nanotechnol.,10, p.7541 (2010).

9. Naczynski, D.J.; Andelman, T.; Pal, D.; Chen, S.; Riman, R.E.; Roth, C.M. \&Moghe, P.V. - Small., 2, p.1631 (2010).PMid:20586056. http:// dx.doi.org/10.1002/smll.200902403

10. Xiong, S.; Yu, B.; Wu, J.; Li, H. \& Lee, R.J. - Biomed. Pharmacother. (2010).In press.

11. Jose, S.; Prema, M.T.; Chacko, A.J.; Thomas, A.C. \&Souto, E.B. Colloids Surf. B Biointerfaces. (2010) In press.

12. Cun, D.; Foged, C.; Yang, M.; Frokjaer, S. \& Nielsen, H.M. - Int. J. Pharm., 5, p.70 (2010).PMid:19836438. http://dx.doi.org/10.1016/j. ijpharm.2009.10.023

13. Chan, A.W. \& Neufeld, R.J. - Biomaterials, 34, p.9040 (2010) PMid:20739057. http://dx.doi.org/10.1016/j.biomaterials.2010.07.111

14. Liu, J.; Qiu, Z.; Wang, S.; Zhou, L. \& Zhang, S. - Biomed. Mater., 6, p.065002 (2010).PMid:20924138. http://dx.doi.org/10.1088/17486041/5/6/065002

15. Akiba, I.;Terada, N.; Hashida, S.; Sakurai, K.; Sato, T.; Shiraishi, K.; Yokoyama, M.; Masunaga, H.; Ogawa, H.; Ito, K. \& Yagi, N. - Langmuir, 10, p.7544 (2010).PMid:20361731. http://dx.doi. org/10.1021/la904355p
16. Lao, L.L.; Peppas, N.A.; Boey, F.Y. \&Venkatraman, S.S. - Int. J. Pharm. (2010). In press.

17. Raval, J.A.; Patel, J.K. \& Patel, M.M. - Acta Pharm., 4, p.455 (2010). PMid:21169137. http://dx.doi.org/10.2478/v10007-010-0034-7

18. Ramtoola, Z.; Lyons, P.; Keohane, K.; Kerrigan, S.W.; Kirby, B.P. \& Kelly, J.G. - J. Pharm. Pharmacol., 1, p.26 (2010).

19. He, C.; Hu, Y.; Yin, L.; Tang, C. \& Yin, C. - Biomaterials, 13, p.3657(2010). PMid:20138662. http://dx.doi.org/10.1016/j.biomaterials.2010.01.065

20. Oliveira, R.B. \& Lima, E.M. - Rev. Brasileira de fármacia, 3, p.29-35(2006).

21. Severino, P.; Dalla Costa, T.C.; Silva, H.; Souto, E.B. \& Santana, M.H.A. - J. Pharm. Biom. Anal. Submetido.

22. Yeh, M.K.; Chen, J.L.; Chiang, C.H. \& Chang, Z.Y. - J. Microencapsul.,24, p.82 (2007). PMid:17438944. http://dx.doi. org/10.1080/02652040601058533

23. Jones, O.G. \&McClements, D.J. - Adv. Colloid Interface Sci. (2010). In press.

24. Ulbrich, K.; Hekmatara, T.; Herbert, E. \& Kreuter J. - Eur. J. Pharm. Biopharm.,71, p.251 (2009). PMid:18805484. http://dx.doi. org/10.1016/j.ejpb.2008.08.021

25. Ulbrich, K.; Michaelis, M.; Rothweiler, F.; Knobloch, T.; Sithisarn, P.; Cinatl, J. \&kreuter, J. - Int. J. Pharm. (2010). In press.

26. Yamada, K.; Yamamoto, N.; Yamada, Y.; Mukohara, T.; Minami, H. \& Tamura, T. - Jpn J. Clin. Oncol.,40, p.404 (2010).PMid:20133335. PMCid:2862657. http://dx.doi.org/10.1093/jjco/hyp19227. Elsadek, B.; Graeser, R.; Esser, N.; Schäfer-Obodozie, C.; Tsurumi, C.; Abu Ajaj, K.; Warnecke, A.; Unger, C.; Saleem, T. \&Kratz, F. - Prostate Cancer Prostatic Dis., 14, p.14 ( 2011).PMid:21042336. http://dx.doi. org/10.1038/pcan.2010.43

28. Kim, T.H.; Jiang, H.H.; Youn, Y.S.; Park, C.W.; Tak, K.K.; Lee, S.; Kim, H.; Jon, S.; Chen, X. \& Lee, K.C. - Int. J. Pharm., 403, p.403 (2011).

29. Guo, L.; Peng, Y.; Yao, J.; Sui, L.; Gu, A. \& Wang, J. - Cancer. Biother.Radiopharm., 25, p.471 (2010). http://dx.doi.org/10.1089/ cbr.2009.0724

30. Katti, D. \&Krishnamurti, N. - J. Microencapsul., 16, p.231 (1999). PMid:10080116. http://dx.doi.org/10.1080/026520499289202

31. Yu, N.Y.; Schindeler, A.; Little, D.G. \&Ruys, A.J. - J. Biomed. Mater. Res. B Appl. Biomater., 93, p.285 (2010).

32. Sengupta, D. \&Heilshorn, S.C. - Tissue Eng. Part B Rev., 16, p.285 (2010).PMid:20141386. http://dx.doi.org/10.1089/ten.teb.2009.0591

33. Md, S.; Ahuja, A.; Khar, R.K.; Baboota, S.; Chuttani, K.; Mishra, A.K. \& Ali, J. - Drug. Deliv. (2010). In press.

34. Vader, P.; Van der Aa, L.J.; Engbersen, J.F.; Storm, G. \&Schiffelers, R.M. - Pharm. Res. (2010). In press.

35. Barakat, N.S. \&Almurshedi, A.S. - J. Microencapsul. (2010). In press.

36. Brandt, F.; Bank, D.; Cross, S.L. \& Weiss, R. - Dermatol. Surg.,36, p.1876 (2010).PMid:20969665. http://dx.doi.org/10.1111/j.15244725.2010.01777.x

37. Akinlade, B.; Elkordy, A.A.; Essa, E.A. \&Elhagar, S. - Sci. Pharm., 78, p.325 (2010).PMid:21179350. PMCid:3002790. http://dx.doi. org/10.3797/scipharm.0912-23

38. Bagchi, S.; Li, W. \&Plakogiannis F. - Pharm. Dev. Technol. (2011). In press.

39. Zhang, L.; Chai, G.; Zeng, X.; He, H.; Xu, H. \& Tang X. - Drug Dev. Ind. Pharm., 36, p.1054 (2010).PMid:20818965. http://dx.doi. org/10.3109/03639041003642081

40. Patel, M.M. \& Amin, A.F. - Drug Deliv. 2010. In press. 
41. Aguilar-de-Leyva, A.; Sharkawi, T.; Bataille, B.; Baylac, G. \&Caraballo, I.- Int. J. Pharm., 14, p.133 (2011).PMid:21094234. http:// dx.doi.org/10.1016/j.ijpharm.2010.11.024

42. Vaghani, S.S.; Patel, S.G.; Jivani, R.R.; Jivani, N.P.; Patel, M.M. \&Borda, R. - Pharm. Dev. Technol. (2010).In press.

43. Dalmoro, A.; Lamberti, G.; Titomanlio, G.; Barba, A.A. \&D’Amore, M. - AAPS PharmSciTech., 11, p.1500 (2010).PMid:20931307. PMCid:3011076. http://dx.doi.org/10.1208/s12249-010-9528-3

44. Notara, M.; Scotchford, C.A.; Grant, D.M.; Weston, N. \& Roberts, G.A. - J. Biomed. Mater. Res. A, 89, p.854 (2009).PMid:18465818. http://dx.doi.org/10.1002/jbm.a.32027

45. Pescosolido, L.; Vermonden, T.; Malda, J.;Censi, R.; Dhert, W.J.;Alhaique, F.; Hennink, W.E. \&Matricardi, P. - ActaBiomater. (2010). In press.

46. Fang, A. \&Cathala, B. - Colloids Surf. B Biointerfaces., 82, p.81 (2010). PMid:20833004. http://dx.doi.org/10.1016/j.colsurfb.2010.08.020

47. Moroni, A.; Drefko, W. \& Thone, G. - Drug Dev. Ind. Pharm., 37, p. 216 (2010).PMid:20973612. http://dx.doi.org/10.3109/03639045.2010.504 726

48. Belgamwar, V.S. \&Surana, S.J. - Chem. Pharm. Bull., 58, p.1168 (2010). http://dx.doi.org/10.1248/cpb.58.1168

49. Zhang, W. \& He, X. - J. Biomech. Eng., 131, p.074515 (2009). PMid:19640151. http://dx.doi.org/10.1115/1.3153326

50. Lin, C. \&Engbersen, J.F. - J. Control. Release.,132, p.267 (2008). PMid:18655813. http://dx.doi.org/10.1016/j.jconrel.2008.06.022

51. Kroencke, T.J.; Scheurig, C.; Lampmann, L.E.; Boekkooi, P.F.; Kissner, L.; Kluner, C.; Weichert, W.; Hamm, B. \&Lohle, P.N. - J. Vasc. Interv. Radiol., 19, p.47, 2008.PMid:18192467. http://dx.doi.org/10.1016/j. jvir.2007.08.019

52. Marino, M.T.; Costello, D.; Baughman, R.; Boss, A.; Cassidy, J.; Damico C, Van Marle, S.; Van Vliet, A. \& Richardson, P.C. - Clin. Pharmacol.Ther., 88, p.243 (2010). http://dx.doi.org/10.1038/ clpt.2010.85

53. Bhise, K.S.; Dhumal, R.S.; Shailesh, B.; Paradkar, A.R. \&Kadam, S.S. - AAPS PharmSciTech., 11, p.226, 2010.PMid:20131020. PMCid:2850499. http://dx.doi.org/10.1208/s12249-010-9379-y

54. Calvo, P.; Remunan-Lopez, C.; Vila-Jato, J.L. \& Alonso, M.J. - Pharm. Res., 14, p.1431 (1997).PMid:9358557. http://dx.doi. org/10.1023/A:1012128907225

55. El-Leithy, E.S.; Shaker, D.S.; Ghorab, M.K. \& Abdel-Rashid, R.S. AAPS PharmSciTech., 11, p.1695 (2010).PMid:21108027. http:// dx.doi.org/10.1208/s12249-010-9544-356. Angadi, S.C.; Manjeshwar, L. S. \&Aminabhavi, T.M. - Int. J. Biol. Macromol.,47, p.171 (2010). PMid:20471411. http://dx.doi.org/10.1016/j.ijbiomac.2010.05.003

57. Brannon Peppas, L. - Int. J. Pharm., 116, p.1 (1995).

58. Qiu, L.Y. \& Bae, Y.H. - Pharm. Res., 23, p.1 (2006).PMid:16392022. http://dx.doi.org/10.1007/s11095-005-9046-2

59. Singh, S. -J. Nanosci. Nanotechnol., 10, p.7906 (2010).

60. Picos, D. R.; Carril, M.G. \& Mena, D.F. Rev. Cubana Farm.,34, p.70 (2000).

61. Khandare, J. \& Haag, R. - Handb. Exp. Pharmacol., 197, p.221 (2010). PMid:20217532. http://dx.doi.org/10.1007/978-3-642-00477-3_8

62. Jain, J.P.; Modi, S. \& Kumar, N. - J. Biomed. Mater. Res. A., 84, p. 740 (2008). PMid:17635032. http://dx.doi.org/10.1002/jbm.a.31456

63. Jain, J.P.; Chitkara, D. \& Kumar, N. - Expert. Opin. Drug Deliv., 5, p.889 (2008). PMid:18712998. http://dx.doi.org/10.1517/17425247.5.8.889

64. Tamargo, R.J.; Epstein, J.I.; Reinhard, C.S.; Chasin, M. \& Brem, H. - J. Biomed. Mater. Res., 23, p.253 (1989).PMid:2708412. http://dx.doi. org/10.1002/jbm.820230209
65. Brem, H.; Kader, A.; Epstein, J.I.; Tamargo, R.J.; Domb, A.; Langer, R.; Leong, K.W. - Sel. Cancer Ther., 5, p.55 (1989).PMid:2772427. http://dx.doi.org/10.1089/sct.1989.5.55

66. Carrillo-Conde, B.; Garza, A.; Anderegg, J. \& Narasimhan, B. - J. Biomed. Mater. Res. A., 95, p.40 (2010).PMid:20740599. http://dx.doi. org/10.1002/jbm.a.32815

67. Lee, W.C. \& Chu, I.M. - J. Biomed. Mater. Res. B Appl. Biomater., 84, p.138, 2008.

68. Gopferich, A. \&Tessmar, J. - Adv. Drug Deliv. Rev., 54, p.911 (2002).

69. Dang, W., Daviau, T. \& Brem, H. - Pharm. Res., 13, p.683 (1996). PMid:8860422. http://dx.doi.org/10.1023/A:1016035229961

70. Katti, D.S.; Lakshmi, S.; Langer, R. \& Laurencin, C.T. - Adv. Drug Deliv. Rev., 54, p.933 (2002). http://dx.doi.org/10.1016/S0169409X(02)00052-2

71. Kipper, M.J.; Wilson, J.H.; Wannemuehler, M.J. \& Narasimhan, B. J. Biomed. Mater. Res. A., 76, p.798 (2006).PMid:16345084. http:// dx.doi.org/10.1002/jbm.a.30545

72. Gao, J.; Niklason, L. \& Zhao, X.M. Langer R. - J. Pharm. Sci., 87, p.246 (1998).PMid:9519161. http://dx.doi.org/10.1021/js970284u

73. Yang, Y.; Xu, Z.; Chen, S.; Gao, Y.; Gu, W.; Chen, L.; Pei, Y. \& Li, Y. - Int. J. Pharm., 353, p.277 (2008). http://dx.doi.org/10.1016/j. ijpharm.2007.11.041

74. Schacht, E.; Vandorpe, J.; Dejardin, S.; Lemmouchi, Y. \& Seymour, L. - Biotechnol. Bioeng., 52, p.102 (1996). http://dx.doi. org/10.1002/(SICI) 1097-0290(19961005)52:1\%3C102::AIDBIT10\%3E3.3.CO;2-B

75. Giavaresi, G.; Tschon, M.; Borsari, V.; Daly, J.H.; Liggat, J.J.; Fini, M.; Bonazzi, V.; Nicolini, A.; Carpi, A.; Morra, M.; Cassinelli, C. \& Giardino, R. - Biomed. Pharmacother., 58, p.411 (2004). http://dx.doi. org/10.1016/S0753-3322(04)00111-8

76. Kawakami, H.; Kanezaki, S.; Sudo, M.; Kanno, M.; Nagaoka, S. \& Kubota, S. - Artif. Organs., 26, p.883 (2002).PMid:12296930. http:// dx.doi.org/10.1046/j.1525-1594.2002.07029.x

77. Chang, Y.; Bender, J.D.; Phelps, M.V. \& Allcock, H.R. Biomacromolecules., 3, p.1364 (2002).PMid:12425677. http://dx.doi. org/10.1021/bm020087b

78. Allcock, H.R.; Steely, L.B.; Kim, S.H.; Kim, J.H. \& Kang, B.K. - Langmuir., 23, p.8103 (2007).PMid:17590030. http://dx.doi. org/10.1021/la700840j

79. Veronese, F.M.; Marsilio, F.; Caliceti, P.; De Filippis, P.; Giunchedi, P. \& Lora, S. - J. Control. Release., 52, p.227 (1998). http://dx.doi. org/10.1016/S0168-3659(97)00098-9

80. Caliceti, P.; Veronese, F.M. \& Lora S. - Int. J. Pharm., 211, p.57 (2000). http://dx.doi.org/10.1016/S0378-5173(00)00588-3

81. Chao, P.; Deshmukh, M.; Kutscher, H.L.; Gao, D.; Rajan, S.S.; Hu, P.; Laskin, D.L.; Stein, S. \& Sinko, P.J. - Anticancer Drugs., 21, p. 65 (2010). PMid:19966540. http://dx.doi.org/10.1097/CAD.0b013e328332a322

82. Sakuma, S.; Sudo, R.; Suzuki, N.; Kikuchi, H.; Akashi, M. \& Hayashi, M. - Int. J. Pharm., 177, p.161 (1999). http://dx.doi.org/10.1016/ S0378-5173(98)00346-9

83. Dunn, S.E.; Brindley, A.; Davis, S.S.; Davies, M.C. \&Illum, L. - Pharm. Res., 11, p.1016 (1994).PMid:7937542. http://dx.doi. org/10.1023/A:1018939521589

84. Moghimi, S.M.; Porter, C.J.; Muir, I.S.; Illum, L. \& Davis, S.S. Biochem. Biophys. Res. Commun., 177, p.861 (1991). http://dx.doi. org/10.1016/0006-291X(91)91869-E

85. Gbadamosi, J.K.; Hunter, A.C. \&Moghimi, S.M. - FEBS Lett., 532, p.338 (2002). http://dx.doi.org/10.1016/0006-291X(91)91869-E

86. Ghassemi, A.H.; Van Steenbergen, M.J.; Talsma, H.; Van Nostrum, C.F.; Crommelin, D.J. \&Hennink, W.E. - Pharm. Res., 27, p.2008 
(2010).PMid:20602152. PMCid:2916118. http://dx.doi.org/10.1007/ s11095-010-0205-8

87. Choudhury, A.; Das, S.; Bahadur, S.; Saha, S. \& Roy, A. - Indian J. Pharm. Sci., 72, p.491 (2010).PMid:21218061. PMCid:3013562. http://dx.doi.org/10.4103/0250-474X.73922

88. Kriwet, B.; Walter, E. \& Kissel, T. - J. Control. Release., 56, p.149 (1998). http://dx.doi.org/10.1016/S0168-3659(98)00078-9

89. Madhusudhan, S.; Panda, A.K.; Parimalakrishnan, S.; Manavalan, R. \& Manna, P.K. - J. Microencapsul., 27, p.281 (2010). PMid:20515261. http://dx.doi.org/10.3109/02652040903131319 90. Das, S.; Suresh, P.K. \& Desmukh, R.- Nanomedicine., 6, p.318 (2010).PMid:19800990. http://dx.doi.org/10.1016/j.nano.2009.09.002

91. Jelvehgari, M.; Barar, J.;Valizadeh, H.; Shadrou, S. \&Nokhodchi, A. Pharm. Dev. Technol., 19, (2010).In press.

92. Ahuja, M.; Dhake, A.S.; Sharma, S.K. \&Majumdar, D.K. - J. Microencapsul., 28, p.37 (2010).PMid:21171815. http://dx.doi.org/10. 3109/02652048.2010.523794

93. Voltan, R.; Castaldello, A.; Brocca-Cofano, E.; Altavilla, G.; Caputo, A.; Laus, M.;Sparnacci, K.; Ensoli, B.; Spaccasassi, S.; Ballestri, M. \& Tondelli, L.- Pharm. Res., 24, p.1870 (2007).PMid:17476465. http:// dx.doi.org/10.1007/s11095-007-9310-8

94. Fundueanu, G.; Mocanu, G.; Constantin, M.; Carpov, A.; Bulacovschi, V.; Esposito, E. \& Nastruzzi C. - J. Pharm., 218, p.13 (2001).

95. Fundueanu, G.; Constantin, M.; Bortolotti, F.; Ascenzi, P.; Cortesi, R. \& Menegatti, E. - Macromol. Biosci.,5, p.955 (2005). PMid:16211551. http://dx.doi.org/10.1002/mabi.200500099

96. Cameron, D.J. \& Shaver M. P.- Chem. Soc. Rev. (2010). In press.

97. Pang, X.; Zhuang, X.; Tang, Z. \& Chen, X. - Biotechnol. J., 5, p.1125 (2010).PMid:21058315. http://dx.doi.org/10.1002/biot.201000135
98. Knight, P.T.; Kirk, J.T.; Anderson, J.M. \& Mather P. T. - J. Biomed. Mater. Res. A., 94, p.333 (2010).

99. Lukaszczyk, J.; Jaszcz, K. \& Srichana, T. - J. Biomater. Sci. $\begin{array}{llll}\text { Polym., 21, p.691 (2010).PMid:20482978. http://dx.doi. } & \end{array}$ org/10.1163/156856209X435826

100. Han, S.I.; Yoo, Y.; Kim, D.K. \& Im, S.S. - Macromol. Biosci., 15, p.200 (2004).

101. Liu, J.W.; Zhao, Q. \& Wan, C.X. - Space Med. Med. Eng., 14, p.308 (2001).

102. Albertsson, A.C. \& Varma, I.K. - Biomacromolecules, 4, p.1466 (2003).PMid:14606869. http://dx.doi.org/10.1021/bm034247a

103. Diaz, R.V.; Llabres, M. \&Evora, C. - J. Control. Release.,59, p.55 (1999). http://dx.doi.org/10.1016/S0168-3659(98)00179-5

104. Voronov, A.; Vasylyev, S.; Kohut, A. \&Peukert, W. - J. Colloid Interface Sci., 15, p.323 (2008).

105. Gorna, K. \& Gogolewski, S. - J. Biomed. Mater. Res., 60, p.592 (2002). PMid:11948518. http://dx.doi.org/10.1002/jbm.10100

106. Xiao, R.Z.; Zeng, Z.W.; Zhou, G.L.; Wang, J.J.; Li, F.Z. \& Wang, A.M. - Int. J. Nanomedicine., 5, p.1057 (2010).

107. Santra, S.; Kaittanis, C. \& Perez, J.M. - Langmuir., 26, p.5364 (2010).PMid:19957939. PMCid:2854188. http://dx.doi.org/10.1021/ la9037843

108. Klapper, M.; Nenov, S.; Haschick, R.; Muller, K. \& Mullen, K. Acc. Chem. Res., 41, p.1190 (2008).PMid:18759463. http://dx.doi. org/10.1021/ar8001206

109. Witt, C. \& Kissel, T. - Eur. J. Pharm. Biopharm.,51, p.171 (2001). http://dx.doi.org/10.1016/S0939-6411(01)00130-8

Enviado: 19/01/11

Aceito: 01/03/11

DOI: $10.1590 / \mathrm{S} 0104-14282011005000061$ 